Article

\title{
Higher Levels of Stress-Related Hair Steroid Hormones Are Associated with the Increased SCORE2 Risk Prediction Algorithm in Apparently Healthy Women
}

\author{
Eglè Mazgelytė 1,*(D), Neringa Burokienè ${ }^{2}$, Agata Vysocka ${ }^{2}$, Martynas Narkevičius ${ }^{2}$, Tomas Petrènas ${ }^{3}$, \\ Andrius Kaminskas ${ }^{3}$, Jurgita Songailiene ${ }^{3}$, Algirdas Utkus ${ }^{3}$ and Dovilè Karčiauskaitè ${ }^{1}$
}

check for updates

Citation: Mazgelytè, E.; Burokienè, N.; Vysocka, A.; Narkevičius, M.; Petrènas, T.; Kaminskas, A.;

Songailienè, J.; Utkus, A.;

Karčiauskaite, D. Higher Levels of Stress-Related Hair Steroid Hormones Are Associated with the Increased SCORE2 Risk Prediction Algorithm in Apparently Healthy Women. J. Cardiovasc. Dev. Dis. 2022, 9, 70. https://doi.org/10.3390/ jcdd 9030070

Academic Editors: Miran Šebeštjen and Juš Kšela

Received: 4 February 2022

Accepted: 25 February 2022

Published: 27 February 2022

Publisher's Note: MDPI stays neutral with regard to jurisdictional claims in published maps and institutional affiliations.

Copyright: (c) 2022 by the authors. Licensee MDPI, Basel, Switzerland. This article is an open access article distributed under the terms and conditions of the Creative Commons Attribution (CC BY) license (https:// creativecommons.org/licenses/by/ $4.0 /)$
1 Department of Physiology, Biochemistry, Microbiology and Laboratory Medicine, Institute of Biomedical Sciences, Faculty of Medicine, Vilnius University, M. K. Čiurlionio st. 21, LT-03101 Vilnius, Lithuania; dovile.karciauskaite@mf.vu.lt

2 Clinics of Internal Diseases, Family Medicine and Oncology, Institute of Clinical Medicine, Faculty of Medicine, Vilnius University, M. K. Čiurlionio st. 21, LT-03101 Vilnius, Lithuania; neringa.burokiene@mf.vu.lt (N.B.); agata.janovska@mf.vu.lt (A.V.); martynas.narkevicius@santa.lt (M.N.)

3 Department of Human and Medical Genetics, Institute of Biomedical Sciences, Faculty of Medicine, Vilnius University, M. K. Čiurlionio st. 21, LT-03101 Vilnius, Lithuania; tomas.petrenas@mf.vu.lt (T.P.); andrius.kaminskas@mf.vu.lt (A.K.); jurgita.songailiene@mf.vu.lt (J.S.); algirdas.utkus@mf.vu.lt (A.U.)

* Correspondence: egle.mazgelyte@mf.vu.lt

\begin{abstract}
Cardiovascular diseases (CVDs) are the major cause of death worldwide. Although the importance of conventional CVD risk factors, including older age, male gender, hypertension, obesity, dyslipidemia and hyperglycemia, is well-studied, psychosocial stress, which is considered an independent CVD risk factor, requires further investigation. Thus, we aimed to investigate the association between long-term secretion of stress-related steroid hormones, including cortisol, cortisone and dehydroepiandrosterone, and the 10-year fatal and non-fatal CVD risk estimated by the SCORE2 risk prediction algorithm, as well as traditional CVD risk factors in a group of apparently healthy women. A total of 145 women (aged 50-64 years) participating in the national CVD prevention program were enrolled in the study. Sociodemographic, lifestyle, health-related characteristics, stress, anxiety and sleep quality indicators were evaluated using specific questionnaires. Anthropometric and arterial blood pressure measures were assessed by trained personnel, lipid and glucose metabolism biomarkers were measured using routine methods, and hair steroid hormone levels were determined by ultra-high-performance liquid chromatography-tandem mass spectrometry. The results showed that higher levels of hair cortisol and cortisone are associated with increased SCORE2 values. Moreover, significant associations between hair glucocorticoids and individual cardiovascular risk factors, including obesity, hypertension, dyslipidemia and hyperglycemia, were found. These findings indicate that stress-related hair steroid hormones might be valuable biomarkers for CVD prediction and prevention.
\end{abstract}

Keywords: cardiovascular disease risk; chronic stress; hair steroid hormones

\section{Introduction}

Cardiovascular disease (CVD) incidence and age-standardized mortality rates are declining in many high-income regions, whereas these only slightly decrease, or at times even increase, in the majority of low- and middle-income countries [1,2]. Globally, CVDs still account for the majority of noncommunicable disease deaths with 17.9 million people affected annually [3]. It is generally accepted that lifestyle risk factors, including unhealthy diet, low physical activity and smoking, are linked to conventional cardiovascular risk factors, such as hypertension, obesity, dyslipidemia and hyperglycemia. Other well-known non-modifiable risk factors are older age, male gender, genetic susceptibility and family history of CVD [1]. Currently, psychosocial stress is considered an independent CVD 
risk factor: epidemiological data suggest that chronic stress at work and in private life is associated with a $40-50 \%$ increased occurrence of coronary heart disease (CHD) [4]. The INTERHEART case-control study, which examined the relationship between modifiable risk factors and the incidence of CHD in 24,767 patients from 52 countries, revealed that selfreported chronic psychosocial stress is associated with a 2.17 times increased myocardial infarction risk after adjusting for traditional cardiovascular risk factors, lifestyle indicators and socioeconomic status [5]. Exposure to chronic stress was related to an increased CVD risk in both men and women, however, it is suggested that women have a higher prevalence of psychosocial factors and are therefore more susceptible and vulnerable to the deleterious effects of stress on CVD [6,7]. Moreover, previous research highlighted the complexities of coronary disease in women, as women tend to have smaller epicardial coronary vessels with more diffuse atherosclerotic disease and are therefore more likely than men to suffer from microvascular coronary disease and endothelial dysfunction [8]. Although women's enrollment in major cardiovascular randomized clinical trials has increased from $21 \%$ between 1986 and 1990 to 33\% between 2011 and 2015, it remains lower than the relative proportion in the disease population, and there is a need for specific studies in women [9].

Despite observational evidence of the relationship between chronic psychosocial stress and adverse health effects, the biological mechanism linking stress and somatic diseases has only recently been fully clarified [10]. In brief, the central nucleus of the amygdala is the primary brain structure involved in emotional perception, generation of fear or anger and physiological response to stressors, as its efferent neurons provide input to the stress system, including the hypothalamic-pituitary-adrenal (HPA) axis and locus caeruleus (LC)/norepinephrine (NE) system. Activation of the HPA axis triggers synthesis of corticotropin-releasing hormone $(\mathrm{CRH})$ and arginine vasopressin in the paraventricular nucleus (PVN) of the hypothalamus. CRH binds to the G-protein-coupled receptors in the anterior lobe of the pituitary gland and induces secretion of adrenocorticotropic hormone $(\mathrm{ACTH})$, which stimulates cortisol synthesis in the adrenocortical cells of the zona fasciculata, regulates androgen secretion by the zona reticularis and participates in control of aldosterone secretion by the zona glomerulosa. The upregulation of the LC/NE system leads to the "fight or flight" reaction, due to enhanced synthesis of epinephrine and norepinephrine in the adrenal medulla. The biological effects of these hormones through genomic and non-genomic pathways include increased insulin resistance, blood pressure, heart rate, visceral adiposity, and impaired immune system response, as well as enhanced systemic and arterial inflammation $[10,11]$.

The major obstacle in chronic stress research is the lack of a universal and validated stress measurement tool or biomarker, as distinct studies use different chronic stress evaluation techniques, including: self-reported questionnaires (e.g., Perceived Stress Scale or the self-reported Life Events Checklist) [12,13]; interviews (e.g., UCLA Life Stress Interview) [14]; and allostatic load index calculation [15] or measurement of cortisol in a variety of biological samples [16-18]. In the last decade, analysis of cortisol in scalp hair was found to be the most promising methodological approach for assessing chronic stress level. The main advantages of using hair cortisol as a biomarker of chronic stress compared with other specimens (i.e., blood serum, saliva, urine) are: the fairly predictable growth rate $(1 \mathrm{~cm} /$ month) that allows retrospective assessment of integrated cortisol secretion; the noninvasive sample collection procedure and small amount of sample required for analysis; the easy sample storage, as samples can be stored at room temperature over long periods of time; and the lack of situational confounding factors, such as circadian rhythmicity, acute stress, smoking, alcohol consumption, food intake and intensive physical exercise [17,19]. Previous studies showed that an increased hair cortisol concentration is associated with long-term unemployment [20], shift work [21], severe chronic pain [22], sleep disorders [23] and psychopathologies, including post-traumatic stress disorder [24], major depression [25] and bipolar disorder [26]. Other, less extensively studied steroid hormones-cortisone and dehydroepiandrosterone (DHEA) — might also be considered stress biomarkers. As mentioned earlier, stress-triggered activation of the HPA axis induces a release of cortisol, 
which is converted to its inactive form, cortisone, by the enzyme 11-beta-hydroxysteroid dehydrogenase type 2 (11 $\beta$-HSD2), though cortisone can be converted back to cortisol by the 11-beta-hydroxysteroid dehydrogenase type 1 (11 $\beta$-HSD1). Thus, simultaneous measurement of hair cortisol and cortisone levels can provide comprehensive information about the cumulative amounts of both active and inactive glucocorticoids in the body [27]. Findings on the use of DHEA as a psychosocial stress biomarker are conflicting, as it was shown that under acute stress conditions ACTH induces DHEA secretion from the zona reticularis, while, at the same time, DHEA plays a protective role acting as an antagonist of glucocorticoids [28]. Previous research showed that exposure to stressful academic events is associated with higher DHEA concentration, as measured in human fingernail samples [29]. However, another pilot study compared hair DHEA levels between subjects who stated a mental burden during the previous three months and those who did not report mental burden and found no evidence of association between mental burden and DHEA concentration [30].

To date, the vast majority of studies has examined the relationship between chronic stress and the prevalence of CVD or CVD risk factors, either by using subjective stress indicators or measuring only the cortisol concentration in hair samples. The current study aimed to investigate the association between long-term secretion of stress-related steroid hormones, including cortisol, cortisone and DHEA, and 10-year fatal and non-fatal CVD risk estimated by SCORE2 risk prediction algorithm, as well as conventional CVD risk factors in a group of apparently healthy 50- to 64-year-old women. Additionally, we analyzed the concordance between hair steroid hormone levels and self-reported stress-related measures, including perceived stress, anxiety and sleep quality.

\section{Materials and Methods}

\subsection{Study Participants}

The open-access program $G^{*}$ Power (version 3.1) was used to calculate the study sample size. After selecting the research significance level $\alpha=0.05$ and the research power $80 \%$, the preliminary size of the research sample was estimated. The chronic stress prevalence parameter was assumed to be $50 \%$, as the exact prevalence of this indicator in the study population is unknown. As such, the cross-sectional study included 145 women (aged 50-64 years) participating in the national cardiovascular disease prevention program. Exclusion criteria were the presence of acute and chronic diseases, including cardiovascular disease, diabetes mellitus and chronic kidney disease, as well as mental diseases and the use of synthetic steroid hormones during the previous 3 months. Participants provided written informed consent before entering the study. The study protocol was approved by the Vilnius Regional Biomedical Research Ethics Committee (No. 2020/8-1254-735). The procedures used in this study adhere to the tenets of the Declaration of Helsinki.

\subsection{Sociodemographic, Lifestyle and Health-Related Characteristics}

Each enrolled individual was asked to fill out a questionnaire to gain information about their sociodemographic (i.e., age, education level, marital status), health-related characteristics (i.e., menopause, physically and psychologically traumatic events during the previous 3 months), lifestyle factors (i.e., smoking status, physical activity level) and hair washing frequency. Studies investigating the influence of hair washing frequency on hair steroid hormone levels showed inconsistent results: Kristensen et al. [31] found no evidence of association between frequency of hair washing and hair cortisol concentration, while Staufenbiel et al. [32] reported that individuals who wash their hair three or more times a week have lower hair cortisol and cortisone levels compared to persons washing their hair twice a week or less. Due to the aforementioned mixed findings, we included hair washing frequency among the factors potentially affecting hair steroid hormone concentrations.

Participants' physical activity level was assessed in different domains, including physical activity at work and leisure time physical activity. Each physical activity domain was measured by a four-category rating scale (score 1-lowest physical activity, score 
4-highest physical activity). Score 1 of physical activity at work was described as "mainly sedentary work, e.g., sitting at the table"; score 2-"necessary to walk during work without lifting of heavy items, e.g., work with the clients"; score 3-“intensive walking during work, carrying heavy items, e.g., post-man's work"; score 4- "heavy, intense physical work, lifting of heavy items, e.g., work of a nurse". Score 1 of physical activity at leisure time was described as "the time mainly spent for reading, watching TV or theatrical performances, etc."; score 2-“minimum 4 times per week going for a walk or wheeling, light work in the garden, fishing, etc."; score 3- "the time mainly spent for running, swimming, tennis or other similar sport"; score 4-"mainly heavy training, running, swimming, skiing, etc., regularly in matches". Subjects were asked to rate their physical activity by selecting one statement from four to best describe their physical activity. The overall physical activity score was obtained by summing up the scores of both physical activity domains. Thus, a possible physical activity score could range from 2 to 8 .

\subsection{Stress, Anxiety and Sleep Quality Measures}

Psychosocial stress level was evaluated using the 10-item version of the Perceived Stress Scale (PSS), designed to measure the degree to which situations in a subject's life are appraised as stressful. Possible total PSS scores range from 0 to 40, with higher scores indicating a higher perceived stress level. PSS scores ranging from 0 to 13 are considered low stress, 14-26-moderate stress and 27-40-high stress [13]. Anxiety level was assessed by the trait scale of State-Trait Anxiety Inventory (STAI-T). The STAI-T scale consists of twenty statements that assess how a person generally feels. Overall STAI-T scores range from 20 to 80, with higher scores indicating a greater trait anxiety level [33]. The Pittsburgh Sleep Quality Index (PSQI) was used to evaluate a subject's sleep quality and disturbances over the period of one month. The PSQI index consists of 19 questions, and the global PSQI index score is calculated by summing up the scores from seven different components, including subjective sleep quality, sleep latency, sleep duration, habitual sleep efficiency, sleep disturbances, use of sleeping medications and daytime dysfunction. The global PSQI index score ranges from 0 to 21 , with higher scores indicating worse sleep quality. It is estimated that a global PSQI index score lower than 5 indicates good sleep quality, while a value equal to or higher than 5 means poor sleep quality [34].

\subsection{Anthropometric Parameters, Biochemical Analyses}

Anthropometric parameters (height, weight, waist circumference), resting arterial blood pressure (systolic and diastolic), and heart rate values were assessed by trained personnel. Additionally, blood samples were collected under fasting conditions and lipid metabolism biomarkers (i.e., total cholesterol, HDL-cholesterol, LDL-cholesterol, triacylglycerols), and glucose concentrations in blood serum were analyzed using routine methods (Architect ci8200, Abbott, Chicago, IL, USA) in the Centre of Laboratory Medicine of Vilnius University Hospital Santaros Klinikos.

\subsection{Cardiovascular Risk Evaluation}

Cardiovascular risk was evaluated using the recently updated SCORE2 prediction model, which estimates 10-year fatal and non-fatal CVD risk in individuals without previous CVD or diabetes, aged 40-69 years, in Europe. The SCORE2 risk prediction algorithm was derived utilizing individual-participant data from 45 cohorts in 13 countries (677,684 individuals; 30,121 CVD events). Distinct SCORE2 charts are used for low, moderate, high and very high CVD risk regions based on region-specific CVD incidence and mortality. Since Lithuania is assigned to the very high risk region, we used the SCORE2 chart developed for populations with a very high CVD risk. In general, the SCORE2 risk prediction algorithm is gender-specific and consists of age, systolic blood pressure and non-HDL-cholesterol measures. The possible SCORE2 values for 50- to 64-year-old women in the very high CVD risk region could range from $4 \%$ to $39 \%$, with $4 \%$ indicating low CVD risk, 5-9\%-moderate, $\geq 10 \%$ - high [2]. 


\subsection{Hair Steroid Hormone Analysis}

Hair samples were collected from the posterior vertex region of the head, as close to the scalp as possible. Samples were stored in foil at room temperature in a dark environment until the analysis. The proximal $3-\mathrm{cm}$ hair segment, reflecting the most recent 3 months, was used for determination of the hair steroid hormone (cortisol, cortisone, dehydroepiandrosterone) levels. A sample preparation procedure was performed using a slightly modified method, as published in our previous paper [35]. Quantitative steroid hormone analysis, utilizing an ultra-high-performance liquid chromatography-tandem mass spectrometry (UHPLC-MS/MS) system, was carried out at the laboratory of the Department of Human and Medical Genetics, Institute of Biomedical Sciences, Faculty of Medicine, Vilnius University.

\subsection{Statistical Analysis}

Statistical analysis was performed using the R software (version 4.0.3). The ShapiroWilk test was used to test the normality of variables. Quantitative variables are presented as mean \pm standard deviation (SD) for normally distributed, or median (interquartile range) (IQR) for non-normally distributed, variables. For categorical variables, absolute and relative frequencies were calculated. Spearman's rank coefficient was used to quantify the strength of the correlation between hair steroid hormones and subjective stress, anxiety and sleep quality indicators, as well as cardiovascular risk factors and SCORE2 risk model values. For comparison of the median (IQR) values of the hair steroid hormone levels among the groups, based on the presence of factors potentially affecting hair steroid hormone levels, lifestyle characteristics or SCORE2 index values, a nonparametric MannWhitney U test or Kruskal-Wallis test was performed. The level of statistical significance was set at 0.05 for two-tailed testing.

\section{Results}

\subsection{Study Group Characteristics}

The results of the self-reported questionnaire showed that the majority of women were married $(73.8 \%)$ and attained a level of higher education (84.1\%). The analysis of lifestyle indicators revealed that almost $90 \%$ of study participants were non-smokers, but more than half of the women used to be physically inactive. Sociodemographic, lifestyle and health-related characteristics of the study group are presented in Table 1.

The analysis of subjective stress level showed that the majority of individuals perceive their lives as non-stressful or feel a moderate stress level (35.9\% and $60.7 \%$, respectively). The global score of PSQI indicated that nearly half of participants (42.0\%) are poor sleepers. According to the manual for the State-Trait Anxiety Inventory [33], the average STAI-T score in a group of 389 healthy women aged 50-69 years was $31.79 \pm 7.78$. In our study group, $80.7 \%$ of women reported higher than average STAI-T score values, indicating an increased anxiety level in the majority of study participants. The descriptive statistics of the self-reported stress, anxiety and sleep quality indicators are presented in Table 2.

The descriptive statistics of anthropometric variables, glucose and lipid metabolism biomarkers, as well as hair steroid hormone levels are depicted in Table 3. The target values for anthropometric and blood pressure measures, as well as for lipid metabolism biomarkers, are reported in the 2021 ESC Guidelines on cardiovascular disease prevention in clinical practice [2]. The results showed that $39.3 \%$ of women had a normal body mass index $\left(18.5-24.9 \mathrm{~kg} / \mathrm{m}^{2}\right), 27.6 \%$ were overweight $\left(25.0-29.9 \mathrm{~kg} / \mathrm{m}^{2}\right)$ and $33.1 \%$ were obese $\left(\geq 30 \mathrm{~kg} / \mathrm{m}^{2}\right)$. Similarly, the majority of subjects $(69.7 \%)$ had higher than recommended $(\geq 80 \mathrm{~cm}$ ) waist circumference values. There was no evidence of hypertension in $67.6 \%$ of women, while $32.4 \%$ had increased systolic $(\geq 140 \mathrm{mmHg}$ ) and/or diastolic blood pressure ( $\geq 90 \mathrm{mmHg}$ ). Furthermore, the results revealed that for the majority of participants $(82.8 \%$ and $75.9 \%$, respectively), LDL-cholesterol and non-HDL cholesterol levels were above the target values $(2.6 \mathrm{mmol} / \mathrm{L}$ and $3.4 \mathrm{mmol} / \mathrm{L}$, respectively). 
Table 1. Sociodemographic, lifestyle and health-related characteristics of the study participants.

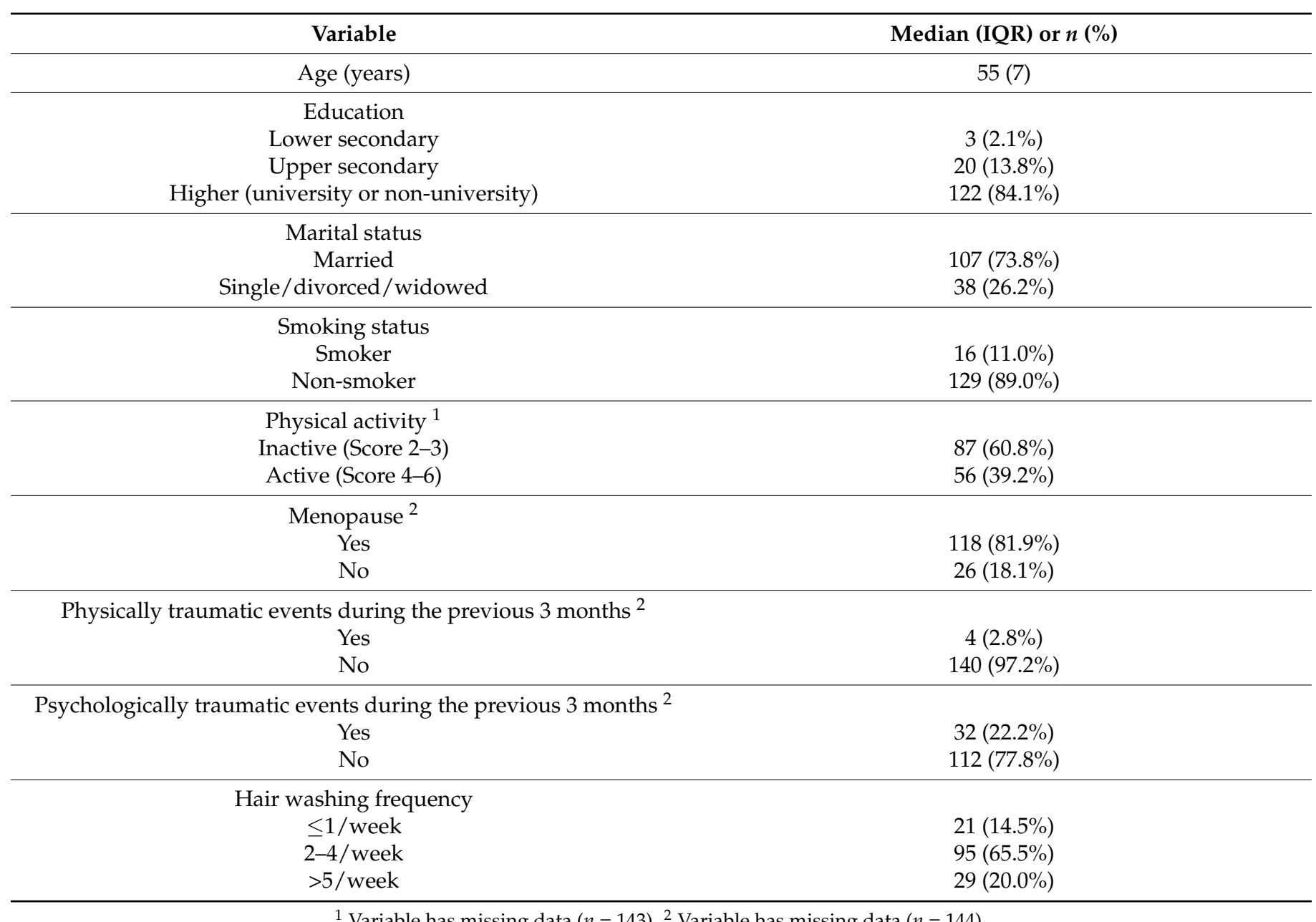

${ }^{1}$ Variable has missing data $(n=143) .{ }^{2}$ Variable has missing data $(n=144)$.

Table 2. Subjective stress, anxiety and sleep quality indicators of the study participants.

\begin{tabular}{ccc}
\hline Variable & Mean \pm SD, Median (IQR) or $\boldsymbol{n}(\%)$ & Range \\
\hline PSS & $15.59 \pm 5.86$ & $0-30$ \\
\hline PSS category & $52(35.9 \%)$ & \\
$0-13$ (low stress) & $88(60.7 \%)$ & \\
14-26 (moderate stress) & $5(3.4 \%)$ & $1-17$ \\
27-30 (high stress) & $5(5.25)$ & \\
\hline PSQI $^{1}$ & & \\
\hline PSQI category $^{1}$ & $83(58.0 \%)$ & \\
$<5$ (good sleeper) & $60(42.0 \%)$ & \\
$\geq 5$ (poor sleeper) & $40.30 \pm 8.87$ \\
\hline STAI-T & $28(19.3 \%)$ & \\
\hline STAI-T category & $117(80.7 \%)$ & \\
$<32$ (lower anxiety) & (higher anxiety) &
\end{tabular}

${ }^{1}$ Variable has missing data $(n=143)$.

\subsection{Hair Steroid Hormones and Cardiovascular Risk Factors}

In the first stage of the analysis, we compared steroid hormone levels between the subject groups, based on the presence of factors potentially affecting hair steroid hormone concentrations. The results showed that no statistically significant differences in hair 
cortisol, cortisone and DHEA concentrations were found between menopausal and nonmenopausal women. Moreover, neither the experience of physically or psychologically traumatic events during the previous three months, nor hair washing frequency, had a significant impact on hair steroid hormone levels. No significant differences in hair cortisol, cortisone and DHEA levels were found among participants with different smoking statuses and physical activity levels (Table 4).

Table 3. Anthropometric indicators, glucose and lipid metabolism biomarkers as well as hair steroid hormone levels of the study participants.

\begin{tabular}{|c|c|c|}
\hline Variable & Mean \pm SD or Median (IQR) & Range \\
\hline Weight (kg) & $74(22)$ & $46-150$ \\
\hline Height $(\mathrm{cm})$ & $165.40 \pm 5.72$ & $149-182$ \\
\hline $\operatorname{BMI}\left(\mathrm{kg} / \mathrm{m}^{2}\right)$ & $26.81(8.18)$ & $17.86-55.77$ \\
\hline Waist circumference $(\mathrm{cm})$ & $85(20)$ & $62-136$ \\
\hline $\mathrm{SBP}(\mathrm{mmHg})$ & $127(21)$ & 89-180 \\
\hline $\mathrm{DBP}(\mathrm{mmHg})$ & $80 \pm 9.08$ & 59-110 \\
\hline HR (bpm) & $76(15)$ & 53-135 \\
\hline Glucose (mmol/L) & $5.39(0.71)$ & $4.1-9.21$ \\
\hline Total cholesterol (mmol/L) & $5.78(1.49)$ & $3.75-10.69$ \\
\hline HDL-cholesterol (mmol/L) & $1.64(0.62)$ & $0.85-3.2$ \\
\hline LDL-cholesterol (mmol/L) & $3.52(1.32)$ & $1.6-8.88$ \\
\hline $\begin{array}{l}\text { Non-HDL-cholesterol } \\
\text { (mmol/L) }\end{array}$ & $4.03(1.54)$ & $2.07-9.47$ \\
\hline $\begin{array}{l}\text { Remnant cholesterol } \\
(\mathrm{mmol} / \mathrm{L})\end{array}$ & $0.53(0.34)$ & $0.24-1.84$ \\
\hline TAG (mmol/L) & $1.160(0.74)$ & $0.52-4.01$ \\
\hline Apo B $(g / L)^{1}$ & $0.92(0.37)$ & $0.093-1.85$ \\
\hline Apo A1 $(\mathrm{g} / \mathrm{L})^{1}$ & $1.56 \pm 0.26$ & $0.86-2.49$ \\
\hline Apo A2 $(\mathrm{g} / \mathrm{L})^{1}$ & $0.35(0.065)$ & $0.22-0.57$ \\
\hline Apo E $(\mathrm{mg} / \mathrm{L})^{1}$ & $44.70(12.32)$ & $23.20-79.00$ \\
\hline Apo A1/Apo B ${ }^{1}$ & $1.62(0.72)$ & $0.62-17.31$ \\
\hline SCORE2 (\%) & $8.00(6.00)$ & $4.00-27.00$ \\
\hline Hair cortisol (ng/g) ${ }^{2}$ & $3.43(6.75)$ & $0.53-117.55$ \\
\hline Hair cortisone $(\mathrm{ng} / \mathrm{g})^{2}$ & $6.65(4.95)$ & $1.49-73.33$ \\
\hline Hair DHEA (ng/g) ${ }^{3}$ & $3.97(4.06)$ & $0.99-22.72$ \\
\hline
\end{tabular}

${ }^{1}$ Variable has missing data $(n=115) .{ }^{2}$ Variable has missing data $(n=144) .{ }^{3}$ Variable has missing data $(n=135)$.

To examine the association between hair steroid hormone levels and cardiovascular disease risk, a SCORE2 index calibrated for very high-risk regions was calculated. SCORE2 estimates 10-year fatal and non-fatal CVD risk in individuals without previous CVD or diabetes aged 40-69 years in Europe. The median (IQR) SCORE2 index value in the study group was $8(6) \%$. Correlation analysis revealed a statistically significant relationship between hair cortisol, as well as hair cortisone levels, and the SCORE2 index values. No significant association between hair DHEA concentration and the SCORE2 index was observed (Figure 1). 
Table 4. Comparison of steroid hormone levels in the subject groups based on the health-related factors, hair washing frequency or lifestyle characteristics.

\begin{tabular}{|c|c|c|c|c|c|c|}
\hline Variable & $\begin{array}{c}\text { Hair Cortisol } \\
\text { (ng/g) } \\
\text { (Median (IQR)) }\end{array}$ & $p$-Value ${ }^{1}$ & $\begin{array}{c}\text { Hair Cortisone } \\
\text { (ng/g) } \\
\text { (Median (IQR)) }\end{array}$ & $p$-Value ${ }^{1}$ & $\begin{array}{c}\text { Hair DHEA } \\
\text { (ng/g) } \\
\text { (Median (IQR)) }\end{array}$ & $p$-Value ${ }^{1}$ \\
\hline \multicolumn{7}{|l|}{ Menopause } \\
\hline Yes & $3.15(6.91)$ & \multirow{2}{*}{0.657} & $6.73(4.88)$ & \multirow{2}{*}{0.342} & $3.60(3.84)$ & \multirow{2}{*}{0.515} \\
\hline No & $3.62(5.97)$ & & $5.29(5.24)$ & & $4.63(4.55)$ & \\
\hline \multicolumn{7}{|l|}{$\begin{array}{l}\text { Psychologically } \\
\text { traumatic events }\end{array}$} \\
\hline Yes & $3.7(5.28)$ & \multirow{2}{*}{0.586} & $6.89(4.26)$ & \multirow{2}{*}{0.543} & $4.07(3.71)$ & \multirow{2}{*}{0.883} \\
\hline No & $3.1(6.92)$ & & $6.43(5.05)$ & & $3.93(4.16)$ & \\
\hline \multicolumn{7}{|l|}{$\begin{array}{l}\text { Hair washing } \\
\text { frequency }\end{array}$} \\
\hline$\leq 1 /$ week & $2.62(2.51)$ & \multirow{3}{*}{0.134} & $6.76(5.12)$ & \multirow{3}{*}{0.966} & $5.04(4.32)$ & \multirow{3}{*}{0.473} \\
\hline 2-4/week & $3.69(6.36)$ & & $6.61(4.23)$ & & $3.47(3.56)$ & \\
\hline$>5 /$ week & $4.06(16.04)$ & & $6.07(5.86)$ & & $4.68(5.18)$ & \\
\hline \multicolumn{7}{|l|}{ Smoking status } \\
\hline Smoker & $3.58(6.96)$ & \multirow{2}{*}{0.849} & $7.26(5.05)$ & \multirow[b]{2}{*}{0.257} & $4.07(4.29)$ & \multirow{2}{*}{0.382} \\
\hline Non-smoker & $3.10(3.50)$ & & $6.24(3.42)$ & & $3.02(2.47)$ & \\
\hline \multicolumn{7}{|l|}{ Physical activity } \\
\hline Inactive & $3.66(9.74)$ & \multirow{2}{*}{0.333} & $6.69(5.73)$ & \multirow[b]{2}{*}{0.362} & $3.58(3.68)$ & \multirow[b]{2}{*}{0.333} \\
\hline Active & $3.58(4.81)$ & & $6.50(4.07)$ & & $4.23(4.73)$ & \\
\hline
\end{tabular}

Results showed that only $4 \%$ of participants had relatively low risk (SCORE2 $<5 \%$ ); moderate risk ( $5 \% \leq$ SCORE2 $\leq 9 \%$ ) was determined for $50 \%$ of women, and $46 \%$ of subjects had high CVD risk (SCORE2 $\geq 10 \%$ ). Since the majority of women had moderate or high CVD risk, we divided the entire study sample into two CVD risk groups: the low or moderate risk group (SCORE2 $<10 \%$ ) vs. the high-risk group (SCORE2 $\geq 10 \%$ ). Comparison of the hair steroid hormone median (IQR) values between the low or moderate and high CVD risk groups revealed statistically significant differences in hair cortisone concentration (5.83 (3.86) ng/g vs. $7.16(7.08) \mathrm{ng} / \mathrm{g}, p=0.002)$ and no significant differences in hair cortisol (3.07 (6.48) $\mathrm{ng} / \mathrm{g}$ vs. $4.07(7.32) \mathrm{ng} / \mathrm{g}, p=0.121)$ and DHEA levels (4.00 (5.20) ng/g vs. 3.93 (3.81) $\mathrm{ng} / \mathrm{g}, p=0.626)$.

Further analysis was performed to examine associations between the hair steroid hormone levels and individual cardiovascular risk indicators, including age, anthropometric characteristics and lipid and glucose metabolism biomarkers. Significant positive correlations were found between hair cortisol concentration and BMI, waist circumference, resting systolic and diastolic blood pressure, as well as apolipoprotein E concentration in blood serum. Similarly, hair cortisone was positively associated with BMI, waist circumference, systolic and diastolic blood pressure and glucose concentration and negatively related to HDL-cholesterol concentration in blood serum. Further, a weak but statistically significant relationship between hair DHEA level and arterial blood pressure was found (Table 5).

\subsection{Hair Steroid Hormones, Self-Reported Stress, Anxiety and Sleep Quality}

Correlation analysis between hair steroids and self-reported stress, anxiety and sleep quality measures revealed significant associations between hair cortisol concentration and PSQI $\left(\mathrm{r}_{\mathrm{s}}=0,181, p=0,030\right)$, sleep disturbances $\left(\mathrm{r}_{\mathrm{s}}=0,169, p=0,043\right)$ and PSS scores $\left(r_{S}=0,170, p=0,041\right)$. Results showed that the PSS values were significantly associated with STAI-T scores $\left(\mathrm{r}_{\mathrm{s}}=0,636, p=2.20 \times 10^{-16}\right)$, global PSQI $\left(\mathrm{r}_{\mathrm{s}}=0.412, p=2.84 \times 10^{-7}\right)$ and its components, including subjective sleep quality $\left(p=1.56 \times 10^{-4}\right)$, sleep latency $(p=0.002)$, sleep duration $(p=0.030)$, sleep disturbances $(p=0.001)$, use of sleeping medication 
$(p=0.038)$ and daytime dysfunction $\left(p=3.59 \times 10^{-8}\right)$. Similarly, STAI-T values were positively correlated with the global PSQI score $\left(\mathrm{r}_{\mathrm{s}}=0.475, p=1.75 \times 10^{-9}\right)$ and six distinct PSQI components (i.e., subjective sleep quality $\left(p=1.70 \times 10^{-6}\right)$, sleep latency $\left(p=1.16 \times 10^{-4}\right)$, sleep duration $(p=0.027)$, sleep disturbances $\left(p=1.62 \times 10^{-5}\right)$, use of sleeping medication $(p=0.030)$ and daytime dysfunction $\left(p=6.23 \times 10^{-12}\right)$. As expected, significant intercorrelations among hair steroid hormone levels were found (i.e., cortisol and cortisone $\left(p=2.20 \times 10^{-16}\right)$, cortisol and DHEA $(p=0.013)$ as well as cortisone and DHEA $(p=0.028)$ (Figure 2).
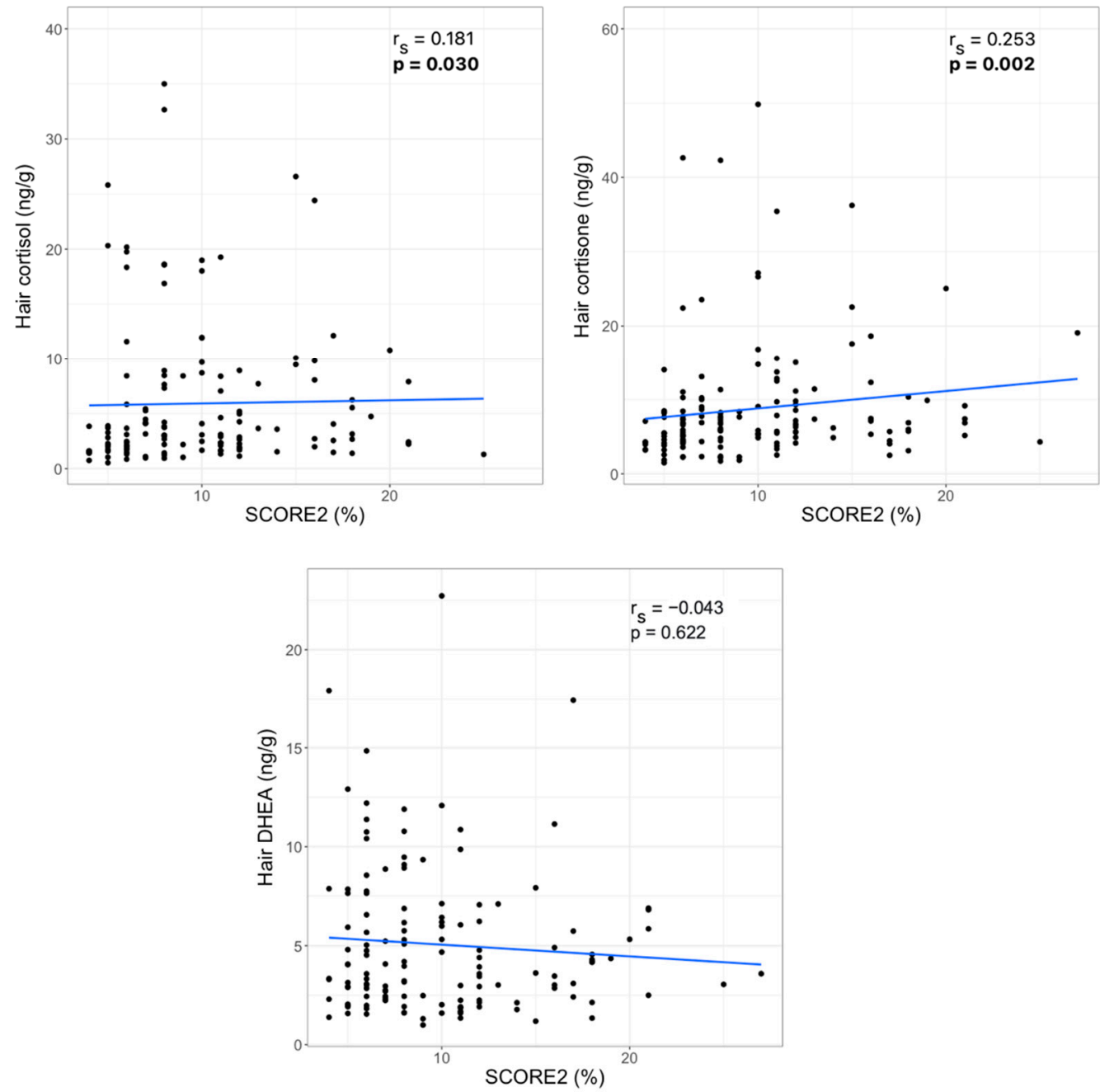

Figure 1. Correlations between hair steroid hormone levels and SCORE2 index $\left(\mathrm{r}_{\mathrm{s}}\right.$-Spearman's correlation coefficient, statistically significant $p$-values are bolded).

Table 5. Correlations between hair steroid hormone levels and age, anthropometric indicators and glucose and lipid metabolism biomarkers.

\begin{tabular}{|c|c|c|c|c|c|c|}
\hline \multirow{2}{*}{ Variable } & \multicolumn{2}{|c|}{ Hair Cortisol (ng/g) } & \multicolumn{2}{|c|}{ Hair Cortisone (ng/g) } & \multicolumn{2}{|c|}{ Hair DHEA (ng/g) } \\
\hline & Spearman's $r$ & $p$-Value ${ }^{1}$ & Spearman's $r$ & $p$-Value ${ }^{1}$ & Spearman's $r$ & $p$-Value ${ }^{1}$ \\
\hline Age (years) & 0.125 & 0.134 & 0.143 & 0.087 & -0.039 & 0.651 \\
\hline BMI $\left(\mathrm{kg} / \mathrm{m}^{2}\right)$ & 0.155 & 0.064 & 0.307 & $1.85 \times 10^{-4}$ & 0.002 & 0.978 \\
\hline $\mathrm{WC}(\mathrm{cm})$ & 0.170 & 0.042 & 0.344 & $2.38 \times 10^{-5}$ & 0.012 & 0.886 \\
\hline $\mathrm{SBP}(\mathrm{mmHg})$ & 0.246 & 0.003 & 0.271 & $1.03 \times 10^{-3}$ & 0.194 & 0.024 \\
\hline
\end{tabular}


Table 5. Cont.

\begin{tabular}{|c|c|c|c|c|c|c|}
\hline \multirow{2}{*}{ Variable } & \multicolumn{2}{|c|}{ Hair Cortisol (ng/g) } & \multicolumn{2}{|c|}{ Hair Cortisone (ng/g) } & \multicolumn{2}{|c|}{ Hair DHEA (ng/g) } \\
\hline & Spearman's $r$ & $p$-Value ${ }^{1}$ & Spearman's $r$ & $p$-Value ${ }^{1}$ & Spearman's $r$ & $p$-Value ${ }^{1}$ \\
\hline $\mathrm{DBP}(\mathrm{mmHg})$ & 0.227 & 0.006 & 0.276 & $7.98 \times 10^{-4}$ & 0.197 & 0.022 \\
\hline HR (bpm) & 0.0003 & 0.997 & 0.130 & 0.122 & 0.023 & 0.795 \\
\hline Glucose (mmol/L) & 0.124 & 0.139 & 0.177 & 0.033 & 0.003 & 0.969 \\
\hline Total cholesterol (mmol/L) & -0.069 & 0.411 & -0.127 & 0.129 & -0.090 & 0.299 \\
\hline HDL-cholesterol (mmol/L) & -0.044 & 0.600 & -0.249 & 0.003 & -0.018 & 0.838 \\
\hline LDL-cholesterol (mmol/L) & -0.010 & 0.234 & -0.107 & 0.201 & -0.078 & 0.366 \\
\hline Non-HDL-cholesterol (mmol/L) & -0.079 & 0.344 & -0.080 & 0.339 & -0.110 & 0.205 \\
\hline Remnant cholesterol (mmol/L) & 0.091 & 0.279 & 0.079 & 0.348 & -0.089 & 0.306 \\
\hline TAG (mmol/L) & 0.090 & 0.283 & 0.077 & 0.356 & -0.082 & 0.343 \\
\hline Apo B (g/L) & 0.098 & 0.300 & 0.070 & 0.462 & -0.019 & 0.845 \\
\hline Apo A1 (g/L) & 0.049 & 0.607 & -0.158 & 0.093 & 0.030 & 0.762 \\
\hline Apo A2 (g/L) & 0.054 & 0.571 & -0.126 & 0.180 & 0.018 & 0.857 \\
\hline Apo E (mg/L) & 0.191 & 0.041 & 0.128 & 0.176 & 0.085 & 0.384 \\
\hline Apo A1/Apo B & -0.024 & 0.803 & -0.102 & 0.279 & 0.027 & 0.781 \\
\hline
\end{tabular}

${ }^{1}$ Statistically significant results $(p<0.05)$ are marked by bold font.

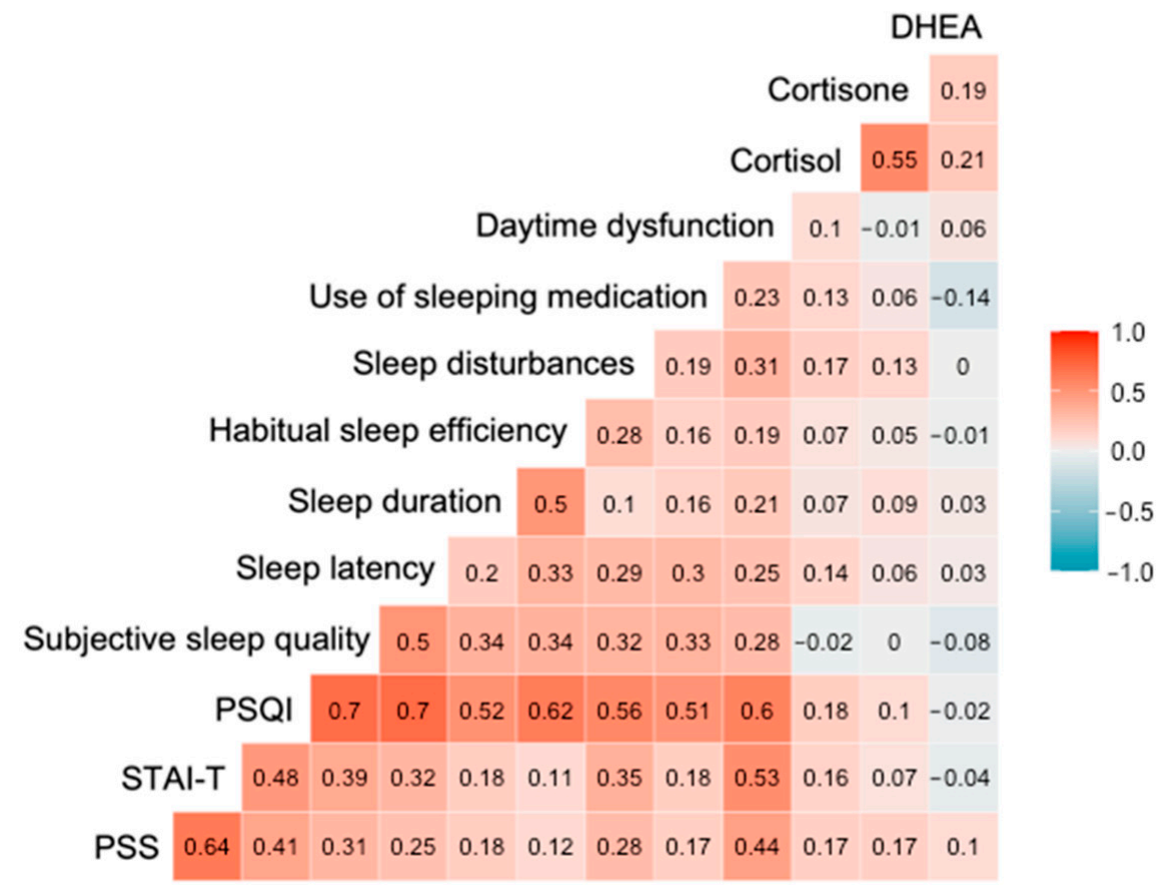

Figure 2. Spearman's correlation matrix of hair steroid hormone levels, stress, anxiety and sleep quality measures (the intensity of color represents the strength of correlation).

\section{Discussion}

The major aim of this study was to examine the link between SCORE2 risk model values, as well as cardiometabolic risk factors, including obesity, dyslipidemia, hyperglycemia, hypertension and hair steroid hormone (i.e., cortisol, cortisone, DHEA) levels in a group of women participating in the national cardiovascular disease prevention program.

The main finding of the current study is the positive correlation between hair glucocorticoids and SCORE2 risk model values. Numerous previous studies reported an association 
between hair cortisol concentration and the incidence of acute coronary syndrome [36] or myocardial infarction [37,38]; elevated hair cortisol level was found to be related to the history of CVD [39], and individuals with coronary heart disease [40] or angiographically documented coronary atherosclerosis [41] had significantly higher hair cortisol levels compared with healthy controls. In contrast to these findings, a study of 3507 participants from an occupational cohort study of British civil servants showed no evidence of an association between hair cortisol concentration and the presence of coronary heart disease or the experience of stroke [42]. However, this is the first study to show that objectively measured chronic stress level is associated with SCORE2 risk model values in apparently healthy women without a diagnosis of acute and chronic diseases. Moreover, it should be noted that the Spearman's correlation coefficient between the hair cortisone and SCORE2 was higher compared with the correlation measured between the hair cortisol and SCORE2 risk model values. Comparison of the hair glucocorticoid levels among women with $\geq 10 \%$ and $<10 \% 10$-year fatal and non-fatal CVD risk showed that only the hair cortisone level differed significantly between groups. These results suggest that cortisone, the inactive form of cortisol, should be considered an additional biologically relevant chronic stress marker in cardiovascular health research. In fact, chronic cortisol exposure is supposed to have an impact on the pathogenesis and progression of CVD as increased cortisol levels affect plasma lipoprotein metabolism, activate gluconeogenesis in the liver and lead to hypertension through distinct molecular mechanisms, including mineralocorticoid-induced sodium retention, plasma volume expansion and inhibition of vasodilator hormones [43]. Since cortisol is enzymatically converted to cortisone, which itself has no biological effect, it is suggested that an assessment of both hair cortisol and cortisone might better reflect the long-term HPA axis activity and chronic stress level [44].

Investigation of the anthropometric data and their relationship with hair glucocorticoid levels showed that both cortisol and cortisone concentrations were positively associated with waist circumference, but only cortisone level was significantly related to BMI. Moreover, the strength of the correlation between hair cortisone concentration and waist circumference was higher compared with the correlation between hair cortisol level and waist circumference. This is in concordance with the results of a recently published meta-analysis [45], where 146 cohorts with 34,342 individuals (aged $53.3 \pm 18.4$ years) in total were analyzed, and significant correlations between hair cortisol or cortisone and BMI, as well as WC, were found. The results of the aforementioned study also indicated that the strongest correlation and the largest effect size were found between hair cortisone level and waist circumference [45]. A possible explanation of hair cortisone being a better predictor of adiposity is that the level of cortisone is assumed to be more stable in the hair shaft and is not affected by the presence of a local HPA-like axis in the hair follicle $[43,45]$.

Our results showed significant associations between all measured steroid hormones and arterial blood pressure values. Conflicting results were found in previous studies investigating the relationship between hypertension and hair cortisol or cortisone levels. A recently published paper [41] reported that the median hair cortisol concentration was significantly higher in hypertensive individuals compared with normotensive subjects. Similarly, Bautista et al. [46] showed that individuals with a higher hair cortisol concentration (above the median of the study sample) were twice as likely to be hypertensive than those with a lower hair cortisol level (below the median of the study sample). A metaanalysis based on findings from 124 (sub)samples [47] identified that only systolic blood pressure was positively associated with hair cortisol concentration, but the relationship between hair cortisol and diastolic blood pressure was overall non-significant. The results of the study conducted by Kuehl et al. [48] were in concordance with the aforementioned findings and, additionally, showed that hair cortisone concentration was not related to either systolic or diastolic blood pressure. In contrast, results of the bivariate Pearson's correlation analysis in a group of 1258 employees of a large aerospace company showed that both their hair cortisol and cortisone levels were significantly associated with mean arterial blood pressure, however, the adjustment for covariates resulted in a non-significant 
relationship between hair cortisol and the mean arterial blood pressure [49]. These findings are in line with the results of the present study as Spearman's correlation coefficient was higher in the hair cortisone-systolic (diastolic) blood pressure association compared to the hair cortisol-systolic (diastolic) blood pressure relationship. To the best of our knowledge, this is the first study to examine the association between hair DHEA level and cardiovascular risk factors. The role of DHEA in hypertension is still not fully understood, but the suggested biological effect of DHEA is based on the stimulation of endothelial NO synthase phosphorylation and results in increased endothelial-derived NO production, which plays a key role as a vasodilator. Thus, DHEA treatment is supposed to be beneficial in reducing systolic and diastolic blood pressure [50]. However, the results of the Multi-Ethnic Study of Atherosclerosis (MESA) showed that a higher DHEA concentration in blood serum was related to a higher incidence of hypertension and a greater increase in blood pressure during follow-up among postmenopausal women free of hypertension at baseline [51]. The results of the present study are in line with the aforementioned findings, as our data revealed a link between hair DHEA concentration and arterial blood pressure. In contrast, Boxer et al. [52] highlighted that six-month oral DHEA supplementation for elderly women had no significant effect on the changes in cardiovascular risk factors, including dyslipidemia, arterial blood pressure, adiposity and fasting glucose level, compared with subjects receiving placebo treatment. A more recently published meta-analysis of 18 randomized clinical trials also reported that DHEA supplementation did not significantly change systolic and diastolic blood pressure, but increased lean body mass and decreased fat mass, when compared to control groups [53].

To date, most studies have focused on the relationship between hair cortisol concentration and glycated hemoglobin level or the prevalence of type 2 diabetes: the results suggested that long-term or repeated HPA axis activation is related to the elevated glycated hemoglobin level $[49,54]$ and higher prevalence of type 2 diabetes $[32,39,42,55]$. In line with the majority of previous studies $[48,49,56]$, no significant association between hair cortisol level and fasting glucose concentration was found in the current study. There are limited data on the relationship between other stress-related steroid hormones, including cortisone or DHEA, and glucose metabolism biomarkers. Our findings suggest that there is a weak but statistically significant association between hair cortisone concentration and fasting serum glucose level. These results are in agreement with a study conducted among Chinese adults where elevated serum cortisone level was found to be associated with an increased prevalence of impaired fasting glucose and type 2 diabetes in a dose-response manner [55].

An analysis of lipid metabolism biomarkers revealed only a few significant associations: hair cortisol concentration was positively related to apolipoprotein $\mathrm{E}$ level, and hair cortisone level was negatively associated with HDL-cholesterol concentration in blood serum. Conflicting results were reported in previous studies where positive [56], negative [49] or no significant associations [48,57] were found between the hair cortisol level and total serum cholesterol concentration. There are a very limited number of studies that have examined the relationship between hair glucocorticoids and HDL-cholesterol level. Stalder et al. [49] performed a bivariate Pearson's correlation analysis in a large occupational cohort and showed that both hair cortisol and cortisone were negatively associated with HDL-cholesterol level $(\mathrm{r}=-0.065, p<0.05, \mathrm{r}=-0.109, p<0.001$, respectively). In contrast, a more recently published population-based prospective cohort study in a group of 2984 children provided no evidence of association between hair cortisol concentration measured at six years old and HDL-cholesterol level evaluated at ages six and ten years and suggested that the relationship of biological stress with cardiometabolic risk factors may develop at later ages [58]. To the best of our knowledge, only one study investigated the association between hair cortisol concentration and serum apolipoprotein profile. Specifically, the aforementioned study examined the link between hair cortisol and ApoA1 and ApoB in a group of children and adolescents aged 4-18 years and showed that hair cortisol concentration was negatively related to ApoA1 level [59]. The present study is the first work to show a weak but statistically significant correlation between hair cortisol 
and serum ApoE concentration. Generally, ApoE is mainly identified in triacylglycerol-rich lipoproteins to mediate the clearance of their remnants, and it is suggested that an increased ApoE concentration is related to a higher prevalence of metabolic syndrome and premature coronary artery disease. However, the clinical significance of ApoE is still under debate as three distinct isoforms, such as ApoE2, ApoE3, ApoE4, might affect cardiovascular health differently [60]. Thus, future research should be focused on the quantitative determination of ApoE isoforms and their relationship with chronic stress biomarkers.

Although hair glucocorticoids are frequently used as a chronic physical or psychological stress biomarkers [17,30], findings on the association between stress-related steroid hormone levels and self-reported perceived stress remain largely inconsistent. Interestingly, in only a few studies, hair cortisol was positively associated with the subjective evaluated stress level. O'Brien et al. [61] reported a weak but statistically significant correlation between the total subjective stress level (Perceived stress scale+ Chaos, Hubbub, and Order scale+City Stress Index) and hair cortisol level in a diverse sample with no prescreening criteria. Another work conducted in a very specific study group (people living with HIV) presented only a nearly significant positive correlation between PSS and hair cortisol, and DHEA was negatively related to stressful life events [62]. The results of other studies showed completely different findings [24,63]. For example, Ling et al. [63] found a significant negative correlation $(\rho=-0.49, p=0.005)$ between a 10-item PSS and the hair cortisol concentration in a group of 35 women from a low-income population, while another study conducted among 164 South African women of mixed ancestry reported no association between the PSS values and hair cortisol but a significant inverse hair cortisol relationship with the Connor-Davidson resilience scale score, indicating that a higher hair cortisol level is related to impaired stress-coping ability [24]. The results of the present study showed a weak but statistically significant correlation between the PSS and hair cortisol level. Although there are large interindividual differences in the person's ability to objectively evaluate psychosocial stress level, and this could explain the discordance between the questionnaires and endocrine stress biomarkers, the current study was conducted during the COVID-19 pandemic, which is particularly stressful for the majority of individuals. Thus, the positive association between the self-reported and biological stress levels might be partially influenced by the stressful life conditions during the pandemic.

We also observed a significant relationship between hair cortisol and the total PSQI values. To date, only a few studies have explored direct association of the HPA axis activity and sleep quality measures. For instance, Wang et al. [64] reported a significant positive correlation between hair cortisol concentration and insomnia, which was diagnosed using the Athens Insomnia scale in a small study group of female employees from a secondary or tertiary hospital. Furthermore, recently published data revealed a mediating effect of the hair cortisol concentration between shift work and sleep disorders [21]. It is suggested that the association between poor sleep quality and increased HPA axis activity is bidirectional: activation of the HPA axis might lead to inadequate sleep duration, diminished slow-wave sleep and sleep fragmentation, while insufficient sleep results in elevated glucocorticoid levels [23]. Thus, our results suggest that both poor sleep quality and higher perceived stress level are associated with an increased hair cortisol concentration, which, in turn, is related to a higher cardiovascular disease risk.

The study has several limitations that need to be addressed in future research. First, the cross-sectional study design does not provide information about causality in the relationship between stress-related steroid hormone secretions and CVD risk. Second, there is no standardized and validated method, nor reference values, for the measurement and analysis of the steroid hormone levels in human hair samples [65]. Third, our study enrolled a homogenous cohort of middle-aged women, where the majority of them were married, highly educated, already at the menopausal period, non-smoking and physically inactive. The scarce number of pre-menopausal women who smoked and experienced physically or psychologically traumatic events during the previous three months made the assessment of how these factors affect the hair steroid hormone levels or CVD risk almost impossible. 
Thus, the findings of the study are applicable only to a population of middle-aged women and should be confirmed in more heterogenous study group including subjects spanning a wide age range with different socioeconomic status and lifestyle habits. Finally, we conducted a pilot study including 145 subjects; therefore, weak but statistically significant associations between the chronic stress biomarkers and CVD risk should be verified in a larger cohort using more complicated statistical modelling techniques.

\section{Conclusions}

Chronic stress biomarkers were found to be associated not only with individual cardiovascular risk factors, including obesity, hypertension, dyslipidemia and hyperglycemia, but also with the SCORE2 risk model which estimates 10-year fatal and non-fatal CVD risk in individuals without previous CVD or diabetes. Although our results showed that only hair cortisol was significantly associated with subjective stress and sleep quality measures, an investigation of the relationship between other hair steroid hormones and CVD risk factors indicated that hair cortisone might be an additional chronic stress biomarker that is even more strongly related to CVD risk in a group of apparently healthy women. Together, these results indicate that stress-related hair steroid hormones, especially cortisol and cortisone, might be valuable biomarkers for CVD prediction and prevention.

Author Contributions: Conceptualization, E.M., D.K. and N.B.; methodology, E.M., D.K., N.B., A.V., M.N., T.P., A.K., J.S. and A.U.; software, E.M.; validation, D.K., N.B., J.S. and A.U.; formal analysis, E.M., T.P. and A.K.; investigation, E.M., D.K., N.B., A.V., M.N., T.P., A.K., J.S. and A.U.; resources, D.K., N.B., J.S. and A.U.; data curation, E.M., N.B., A.V. and M.N.; writing-original draft preparation, E.M.; writing-review and editing, D.K., N.B., A.V., M.N., T.P., A.K., J.S. and A.U.; visualization, E.M.; supervision, D.K., N.B., J.S. and A.U.; project administration, D.K. All authors have read and agreed to the published version of the manuscript.

Funding: This research received no external funding.

Institutional Review Board Statement: The study was conducted in accordance with the Declaration of Helsinki and approved by the Vilnius Regional Biomedical Research Ethics Committee (No. 2020/8-1254-735).

Informed Consent Statement: Informed consent was obtained from all subjects involved in the study.

Data Availability Statement: The data supporting the reported results are archived in the National Open Access Research Data Archive (MIDAS) at www.midas.lt. (accessed on 24 October 2021).

Conflicts of Interest: The authors declare no conflict of interest.

\section{References}

1. Jagannathan, R.; Patel, S.A.; Ali, M.K.; Narayan, K.M.V. Global Updates on Cardiovascular Disease Mortality Trends and Attribution of Traditional Risk Factors. Curr. Diab. Rep. 2019, 19, 1-12. [CrossRef] [PubMed]

2. Visseren, F.L.J.; MacH, F.; Smulders, Y.M.; Carballo, D.; Koskinas, K.C.; Bäck, M.; Benetos, A.; Biffi, A.; Boavida, J.M.; Capodanno, D.; et al. 2021 ESC Guidelines on cardiovascular disease prevention in clinical practice. Eur. Heart J. 2021, 42, 3227-3337. [CrossRef] [PubMed]

3. Jones, C.; Gwenin, C. Cortisol level dysregulation and its prevalence-Is it nature's alarm clock? Physiol. Rep. 2021, 8, 1-9. [CrossRef]

4. Steptoe, A.; Kivimäki, M. Stress and cardiovascular disease. Nat. Rev. Cardiol. 2012, 9, 360-370. [CrossRef] [PubMed]

5. Rosengren, A.; Hawken, S.; Ônpuu, S.; Sliwa, K.; Zubaid, M.; Almahmeed, W.A.; Blackett, K.N. Association of psychosocial risk factors with risk of acute myocardial infarction in 11119 cases and 13648 controls from 52 countries (the INTERHEART study): Case-control study. Lancet 2004, 364, 953-962. [CrossRef]

6. Dhaibar, H.A.; Cruz-Topete, D. Predisposition of Women to Cardiovascular Diseases: A Side-Effect of Increased Glucocorticoid Signaling During the COVID-19 Pandemic? Front. Glob. Women's Health 2021, 2, 1-10. [CrossRef]

7. Vaccarino, V.; Bremner, J.D. Behavioral, emotional and neurobiological determinants of coronary heart disease risk in women. Neurosci. Biobehav. Rev. 2017, 74, 297-309. [CrossRef]

8. Geraghty, L.; Figtree, G.A.; Schutte, A.E.; Patel, S.; Woodward, M.; Arnott, C. Cardiovascular Disease in Women: From Pathophysiology to Novel and Emerging Risk Factors. Hear. Lung Circ. 2021, 30, 9-17. [CrossRef]

9. Gong, I.Y.; Tan, N.S.; Ali, S.H.; Lebovic, G.; Mamdani, M.; Goodman, S.G.; Ko, D.T.; Laupacis, A.; Yan, A.T. Temporal Trends of Women Enrollment in Major Cardiovascular Randomized Clinical Trials. Can. J. Cardiol. 2019, 35, 653-660. [CrossRef] 
10. Dar, T.; Radfar, A.; Abohashem, S.; Pitman, R.K.; Tawakol, A.; Osborne, M.T. Psychosocial Stress and Cardiovascular Disease. Curr. Treat. Options Cardiovasc. Med. 2019, 21,1-17. [CrossRef]

11. Nicolaides, N.C.; Kyratzi, E.; Lamprokostopoulou, A.; Chrousos, G.P.; Charmandari, E. Stress, the stress system and the role of glucocorticoids. Neuroimmunomodulation 2014, 22, 6-19. [CrossRef] [PubMed]

12. Gray, M.J.; Litz, B.T.; Hsu, J.L.; Lombardo, T.W. Psychometric properties of the life events checklist. Assessment 2004, 11, 330-341. [CrossRef] [PubMed]

13. Cohen, S.; Kamarck, T.; Mermelsten, R. A Global Measure of Perceived Stress. J. Health Soc. Behav. 1983, 24, 385-396. [CrossRef]

14. Ostiguy, C.S.; Ellenbogen, M.A.; Linnen, A.M.; Walker, E.F.; Hammen, C.; Hodgins, S. Chronic stress and stressful life events in the offspring of parents with bipolar disorder. J. Affect. Disord. 2009, 114, 74-84. [CrossRef]

15. Mauss, D.; Jarczok, M.N. The streamlined allostatic load index is associated with perceived stress in life-findings from the MIDUS study. Stress 2021, 24, 404-412. [CrossRef]

16. Phillips, R.; Kraeuter, A.K.; McDermott, B.; Lupien, S.; Sarnyai, Z. Human nail cortisol as a retrospective biomarker of chronic stress: A systematic review. Psychoneuroendocrinology 2021, 123. [CrossRef] [PubMed]

17. Russell, E.; Koren, G.; Rieder, M.; Van Uum, S. Hair cortisol as a biological marker of chronic stress: Current status, future directions and unanswered questions. Psychoneuroendocrinology 2012, 37, 589-601. [CrossRef] [PubMed]

18. Hellhammer, D.H.; Wüst, S.; Kudielka, B.M. Salivary cortisol as a biomarker in stress research. Psychoneuroendocrinology 2009, 34, 163-171. [CrossRef]

19. Stalder, T.; Kirschbaum, C. Analysis of cortisol in hair - State of the art and future directions. Brain. Behav. Immun. 2012, 26, 1019-1029. [CrossRef]

20. Dettenborn, L.; Tietze, A.; Bruckner, F.; Kirschbaum, C. Higher cortisol content in hair among long-term unemployed individuals compared to controls. Psychoneuroendocrinology 2010, 35, 1404-1409. [CrossRef]

21. Zhang, Y.; Shen, J.; Zhou, Z.; Sang, L.; Zhuang, X.; Chu, M.; Tian, T.; Xiao, J.; Lian, Y. Relationships among shift work, hair cortisol concentration and sleep disorders: A cross-sectional study in China. BMJ Open 2020, 10, 1-7. [CrossRef] [PubMed]

22. Van Uum, S.H.M.; Sauvé, B.; Fraser, L.A.; Morley-Forster, P.; Paul, T.L.; Koren, G. Elevated content of cortisol in hair of patients with severe chronic pain: A novel biomarker for stress. Stress 2008, 11, 483-488. [CrossRef] [PubMed]

23. El Mlili, N.; Ahabrach, H.; Cauli, O. Hair cortisol concentration as a biomarker of sleep quality and related disorders. Life 2021, 11, 81. [CrossRef] [PubMed]

24. van den Heuvel, L.L.; Acker, D.; du Plessis, S.; Stalder, T.; Suliman, S.; Thorne, M.Y.; Kirschbaum, C.; Seedat, S. Hair cortisol as a biomarker of stress and resilience in South African mixed ancestry females. Psychoneuroendocrinology 2020, 113, 104543. [CrossRef] [PubMed]

25. Steudte-Schmiedgen, S.; Wichmann, S.; Stalder, T.; Hilbert, K.; Muehlhan, M.; Lueken, U.; Beesdo-Baum, K. Hair cortisol concentrations and cortisol stress reactivity in generalized anxiety disorder, major depression and their comorbidity. J. Psychiatr. Res. 2017, 84, 184-190. [CrossRef]

26. Coello, K.; Munkholm, K.; Nielsen, F.; Vinberg, M.; Kessing, L.V. Hair cortisol in newly diagnosed bipolar disorder and unaffected first-degree relatives. Psychoneuroendocrinology 2019, 99, 183-190. [CrossRef]

27. Davison, B.; Singh, G.R.; McFarlane, J. Hair cortisol and cortisone as markers of stress in indigenous and non-indigenous young adults. Stress 2019, 22, 210-220. [CrossRef]

28. Dutheil, F.; de Saint Vincent, S.; Pereira, B.; Schmidt, J.; Moustafa, F.; Charkhabi, M.; Bouillon-Minois, J.B.; Clinchamps, M. DHEA as a Biomarker of Stress: A Systematic Review and Meta-Analysis. Front. Psychiatry 2021, 12, 1-14. [CrossRef]

29. Doan, S.N.; DeYoung, G.; Fuller-Rowell, T.E.; Liu, C.; Meyer, J. Investigating relations among stress, sleep and nail cortisol and DHEA. Stress 2018, 21, 188-193. [CrossRef]

30. Ullmann, E.; Barthel, A.; Petrowski, K.; Stalder, T.; Kirschbaum, C.; Bornstein, S.R. Pilot study of adrenal steroid hormones in hair as an indicator of chronic mental and physical stress. Nat. Sci. Reports 2016, 6, 1-7. [CrossRef]

31. Kristensen, S.K.; Larsen, S.C.; Olsen, N.J.; Fahrenkrug, J.; Heitmann, B.L. Hair dyeing, hair washing and hair cortisol concentrations among women from the healthy start study. Psychoneuroendocrinology 2017, 77, 182-185. [CrossRef] [PubMed]

32. Staufenbiel, S.M.; Penninx, B.W.J.H.; de Rijke, Y.B.; van den Akker, E.L.T.; van Rossum, E.F.C. Determinants of hair cortisol and hair cortisone concentrations in adults. Psychoneuroendocrinology 2015, 60, 182-194. [CrossRef] [PubMed]

33. Spielberger, C.D. Manual for the State-Trait Anxiety Inventory (STAI); Mind Garden, Inc.: Menlo Park, CA, USA, 1968.

34. Buysse, D.J.; Reynolds, C.F.; Monk, T.H.; Berman, S.R.; Kupfer, D.J. The Pittsburgh Sleep Quality Index: A new instrument for psychiatric practice and research. Psychiatry Res. 1989, 28, 193-213. [CrossRef]

35. Mažeikienė, A.; Bekesiene, S.; Karčiauskaitè, D.; Mazgelytė, E.; Larsson, G.; Petrènas, T.; Kaminskas, A.; Songailienė, J.; Utkus, A.; Vaičaitienè, R.; et al. The Association between Endogenous Hair Steroid Hormones and Social Environmental Factors in a Group of Conscripts during Basic Military Training. Int. J. Environ. Res. Public Health 2021, 18, 12239. [CrossRef] [PubMed]

36. Izawa, S.; Miki, K.; Tsuchiya, M.; Yamada, H.; Nagayama, M. Hair and fingernail cortisol and the onset of acute coronary syndrome in the middle-aged and elderly men. Psychoneuroendocrinology 2019, 101, 240-245. [CrossRef]

37. Faresjö, T.; Strömberg, S.; Jones, M.; Stomby, A.; Karlsson, J.E.; Östgren, C.J.; Faresjö, Å.; Theodorsson, E. Elevated levels of cortisol in hair precede acute myocardial infarction. Sci. Rep. 2020, 10, 1-8. [CrossRef] [PubMed]

38. Pereg, D.; Gow, R.; Mosseri, M.; Lishner, M.; Rieder, M.; Van Uum, S.; Koren, G. Hair cortisol and the risk for acute myocardial infarction in adult men. Stress 2011, 14, 73-81. [CrossRef] 
39. Manenschijn, L.; Schaap, L.; Van Schoor, N.M.; Van Der Pas, S.; Peeters, G.M.E.E.; Lips, P.; Koper, J.W.; Van Rossum, E.F.C. High long-term cortisol levels, measured in scalp hair, are associated with a history of cardiovascular disease. J. Clin. Endocrinol. Metab. 2013, 98, 2078-2083. [CrossRef]

40. Bossé, S.; Stalder, T.; D'Antono, B. Childhood Trauma, Perceived Stress, and Hair Cortisol in Adults with and Without Cardiovascular Disease. Psychosom. Med. 2018, 80, 393-402. [CrossRef]

41. Nafisa, A.; Wattoo, F.H.; Qayyum, M.; Gulfraz, M. The association between chronic stress, hair cortisol, and angiographically documented coronary atherosclerosis, a case-control study. Stress 2021, 1-8. [CrossRef]

42. Abell, J.G.; Stalder, T.; Ferrie, J.E.; Shipley, M.J.; Kirschbaum, C.; Kivimäki, M.; Kumari, M. Assessing cortisol from hair samples in a large observational cohort: The Whitehall II study. Psychoneuroendocrinology 2016, 73, 148-156. [CrossRef]

43. Iob, E.; Steptoe, A. Cardiovascular Disease and Hair Cortisol: A Novel Biomarker of Chronic Stress. Curr. Cardiol. Rep. 2019, 21. [CrossRef] [PubMed]

44. Vanaelst, B.; Michels, N.; De Vriendt, T.; Huybrechts, I.; Vyncke, K.; Sioen, I.; Bammann, K.; Rivet, N.; Raul, J.S.; Molnar, D.; et al. Cortisone in hair of elementary school girls and its relationship with childhood stress. Eur. J. Pediatr. 2013, 172, 843-846. [CrossRef] [PubMed]

45. van der Valk, E.; Abawi, O.; Mohseni, M.; Abdelmoumen, A.; Wester, V.; van der Voorn, B.; Iyer, A.; van den Akker, E.; Hoeks, S.; van den Berg, S.; et al. Cross-sectional relation of long-term glucocorticoids in hair with anthropometric measurements and their possible determinants: A systematic review and meta-analysis. Obes. Rev. 2021, 1-21. [CrossRef]

46. Bautista, L.E.; Bajwa, P.K.; Shafer, M.M.; Malecki, K.M.C.; McWilliams, C.A.; Palloni, A. The relationship between chronic stress, hair cortisol and hypertension. Int. J. Cardiol. Hypertens. 2019, 2, 1-6. [CrossRef]

47. Stalder, T.; Steudte-Schmiedgen, S.; Alexander, N.; Klucken, T.; Vater, A.; Wichmann, S.; Kirschbaum, C.; Miller, R. Stress-related and basic determinants of hair cortisol in humans: A meta-analysis. Psychoneuroendocrinology 2017, 77, 261-274. [CrossRef]

48. Kuehl, L.K.; Hinkelmann, K.; Muhtz, C.; Dettenborn, L.; Wingenfeld, K.; Spitzer, C.; Kirschbaum, C.; Wiedemann, K.; Otte, C. Hair cortisol and cortisol awakening response are associated with criteria of the metabolic syndrome in opposite directions. Psychoneuroendocrinology 2015, 51, 365-370. [CrossRef]

49. Stalder, T.; Kirschbaum, C.; Alexander, N.; Bornstein, S.R.; Gao, W.; Miller, R.; Stark, S.; Bosch, J.A.; Fischer, J.E. Cortisol in hair and the metabolic syndrome. J Clin Endocrinol Metab 2013, 98, 2573-2580. [CrossRef]

50. Savineau, J.P.; Marthan, R.; Dumas De La Roque, E. Role of DHEA in cardiovascular diseases. Biochem. Pharmacol. 2013, 85, 718-726. [CrossRef]

51. Wang, L.; Szklo, M.; Folsom, A.R.; Cook, N.R.; Gapstur, S.M.; Ouyang, P. Endogenous sex hormones, blood pressure change, and risk of hypertension in postmenopausal women: The Multi-Ethnic Study of Atherosclerosis. Atherosclerosis 2012, 224, 228-234. [CrossRef]

52. Boxer, R.S.; Kleppinger, A.; Brindisi, J.; Feinn, R.; Burleson, J.A.; Kenny, A.M. Effects of dehydroepiandrosterone (DHEA) on cardiovascular risk factors in older women with frailty characteristics. Age Ageing 2010, 39, 451-458. [CrossRef]

53. Wang, F.; He, Y.O.; Santos, H.; Sathian, B.; Price, J.C.; Diao, J. The effects of dehydroepiandrosterone (DHEA) supplementation on body composition and blood pressure: A meta-analysis of randomized clinical trials. Steroids 2020, 163, 108710. [CrossRef] [PubMed]

54. Lehrer, H.M.; Dubois, S.K.; Maslowsky, J.; Laudenslager, M.L.; Steinhardt, M.A. Hair cortisol concentration and glycated hemoglobin in African American adults. Psychoneuroendocrinology 2016, 72, 212-218. [CrossRef]

55. Wei, D.; Liu, X.; Huo, W.; Yu, S.; Li, L.; Wang, C.; Mao, Z. Serum cortisone and glucocorticoid receptor gene (NR3C1) polymorphism in human dysglycemia. Hormones 2020, 19, 385-393. [CrossRef] [PubMed]

56. Mazgelytė, E.; Karčiauskaitè, D.; Linkevičiūtè, A.; Mažeikienè, A.; Burokienė, N.; Matuzevičienė, R.; Radzevičius, M.; Janiulionienè, A.; Jakaitienè, A.; Dindienè, L.; et al. Association of hair cortisol concentration with prevalence of major cardiovascular risk factors and Allostatic load. Med. Sci. Monit. 2019, 25, 3573-3582. [CrossRef]

57. Wester, V.L.; Noppe, G.; Savas, M.; van den Akker, E.L.T.; de Rijke, Y.B.; van Rossum, E.F.C. Hair analysis reveals subtle HPA axis suppression associated with use of local corticosteroids: The Lifelines cohort study. Psychoneuroendocrinology 2017, 80, 1-6. [CrossRef] [PubMed]

58. Vehmeijer, F.O.L.; Santos, S.; De Rijke, Y.B.; Van Den Akker, E.L.T.; Felix, J.F.; Van Rossum, E.F.C.; Jaddoe, V.W.V. Associations of Hair Cortisol Concentrations with Cardiometabolic Risk Factors in Childhood. J. Clin. Endocrinol. Metab. 2021, 106, E3400-E3413. [CrossRef] [PubMed]

59. Genitsaridi, S.M.; Karampatsou, S.; Papageorgiou, I.; Mantzou, A.; Papathanasiou, C.; Kassari, P.; Paltoglou, G.; Kourkouti, C.; Charmandari, E. Hair Cortisol Concentrations in Overweight and Obese Children and Adolescents. Horm. Res. Paediatr. 2020, 92, 229-236. [CrossRef] [PubMed]

60. Marais, A.D. Apolipoprotein E in lipoprotein metabolism, health and cardiovascular disease. Pathology 2019, 51, 165-176. [CrossRef] [PubMed]

61. O'Brien, K.M.; Tronick, E.Z.; Moore, C.L. Relationship between hair cortisol and perceived chronic stress in a diverse sample. Stress Health 2013, 29, 337-344. [CrossRef]

62. Qiao, S.; Li, X.; Zilioli, S.; Chen, Z.; Deng, H.; Pan, J.; Guo, W. Hair measurements of cortisol, DHEA, and DHEA to cortisol ratio as biomarkers of chronic stress among people living with HIV in China: Known-group validation. PLoS One 2017, 12, 1-15. [CrossRef] [PubMed] 
63. Ling, J.; Xu, D.; Robbins, L.B.; Meyer, J.S. Does hair cortisol really reflect perceived stress? Findings from low-income motherpreschooler dyads. Psychoneuroendocrinology 2020, 111, 104478. [CrossRef] [PubMed]

64. Wang, C.; Dai, J.; Li, J. Mediating effects of hair cortisol on the mutual association of job burnout and insomnia: A retrospective exploratory study. J. Psychiatr. Res. 2019, 117, 62-67. [CrossRef]

65. Greff, M.J.E.; Levine, J.M.; Abuzgaia, A.M.; Elzagallaai, A.A.; Rieder, M.J.; van Uum, S.H.M. Hair cortisol analysis: An update on methodological considerations and clinical applications. Clin. Biochem. 2019, 63, 1-9. [CrossRef] [PubMed] 